\title{
Incidence of Neonatal Sepsis in the Neonatal Intensive Care unit: A prospective study at Al Batool Teaching Hospital in Diyala Governorate
}

Sura Qais Mahmood Almaroof (FICMS, CABP) ${ }^{\mathbf{1}}$, Imad Mahmood Enad (FICMS) ${ }^{2}$, Shaima Hussein Alwan (FICMS $)^{3}$ and Issam Tariq Abdul Wahaab $(\mathrm{PhD})^{4}$

\section{Abstract}

Background:Sepsis is regarded as one of the most common causes of morbidity and mortality in neonates despite of recent advances in neonatal intensive care unit technologies. More than $40 \%$ of deaths among children below five years occur in the neonatal period and this accounts for about 3.1 million newborn deaths each year.

Objective: To estimate the incidence of neonatal sepsis in the neonatal intensive care unit in Al-Batool teaching hospital in Diyala governorate.

Patients and Methods: A sample of 1200 patients was prospectively collected over a period of 10 months extending from the 1st of Dec. 2018 till the 1st of Oct. 2019 in the neonatal intensive care unit at Al-Batool teaching hospital. All the admitted cases with clinical signs of sepsis at the time of admission or who developed sepsis during their hospital stay were assessed depending on the clinical and laboratory investigations.

Results: This study revealed that the incidence of neonatal sepsis was $8.8 \%$. There were significant relationships between development of neonatal sepsis and each of gestational age, state of amniotic membrane, mode of delivery and maternal fever ( $p$-value $=0.0001$ for each). In addition this study showed that there was insignificant relationship between the development of neonatal sepsis and gender of neonates, p-value equal to 0.463 .

Conclusion: The occurrence of neonatal sepsis depends on the presence of many factors that could be prenatal, perinatal and postnatal. In addition to that the infection control programs play an important role in controlling neonatal sepsis in the neonatal intensive care units. Therefore the incidence rate of neonatal sepsis reflect the quality of the provided health services in the health institutions and this might explain the relatively accepted rate of sepsis in our institution in relation to other studies as it was $8.8 \%$.

Keywords: Neonatal sepsis, Incidence, Risk factors.

Corresponding Author: Suraqais16@gmail.com

Received: $3^{\text {th }}$ December 2019

Accepted: $5^{\text {th }}$ January 2020

DOI:https://doi.org/10.26505/DJM.18015071203

${ }^{1,2,3}$ Department of Pediatrics- Neonatology Unit-Diyala Health Directorate Diyala -Iraq.

${ }^{4}$ College of Medicine-University of Baghdad- Baghdad -Iraq. 


\section{Introduction}

Sepsis is regarded as one of the most common causes of morbidity and mortality in neonates despite of recent advances in neonatal intensive care unit technologies [1]. More than $40 \%$ of deaths among children below five years occur in the neonatal period and this accounts for about 3.1 million newborn deaths each year [2]. The majority of death cases occur in developing countries and about 1 million of these deaths are due to infectious causes including neonatal sepsis, meningitis, and pneumonia [3]. In addition those who survive neonatal sepsis are at risk of developing short and long term neurological and developmental morbidity [4-6]. Neonatal sepsis is defined as a clinical syndrome occurring in an infant aged $\leq 28$ days of life. Sepsis is manifested by systemic signs of infection and isolation of the causative bacterial pathogen from the blood [7]. Diagnosis of neonatal sepsis can be reach clinically at time of presentation but it is usually difficult because of the nonspecific signs. In the other hand laboratory diagnosis is considered time consuming. Therefore, diagnosis and management of neonatal sepsis are a great challenge facing neonatologists in neonatal intensive care units. These facts make the use of the empirical antibiotic necessary till the results of blood culture ruled out sepsis [8]. Neonatal sepsis is caused by Gram positive and negative bacteria and Candida [9]. The organisms causing sepsis differ from place to another and altered over time [10] , [11]. Many conditions can increase the chance of development of neonatal sepsis and these can influence the incidence rate of neonatal sepsis. The incidence rate also differs from hospital to another hospital depending on the risk factors predisposing the infants to infection [9], [12].

\section{Patients and Methods}

A sample of 1200 patients was prospectively collected over a period of 10 months extending from the 1st of Dec. 2018 till the 1st of Oct. 2019 in the neonatal intensive care unit at Al-Batool teaching hospital. All cases with clinical signs of sepsis at first time of presentation or who developed sepsis during their hospitalization were assessed depending on the clinical and laboratory investigations including: highly selective C-reactive protein (HSCRP), complete blood count (CBC), Blood cultures and chest X-ray (CXR). Sepsis is defined as the presence of the following: the presence of two or more clinical signs of sepsis like respiratory distress, poor reflexes, lethargy, apnea, bradycardia, convulsions, abdominal distension, and gastrointestinal bleeding, abnormal CBC and positive CRP and positive culture in addition to the presence of one or more of the possible risk factors for development of neonatal sepsis like prematurity, chorioamnionitis, maternal fever [13].

Data for possible risk factors of neonatal sepsis were gathered focusing on gestational age, mode of delivery, premature rupture of amniotic membranes and maternal fever during pregnancy. Neonatal sepsis is classified according to its onset of development in relation to age of neonates into: early onset neonatal sepsis which occurs 
in neonate $\leq 72$ hours of life and late onset neonatal sepsis which occurs in neonate $>72$ hours of life [14].Blood samples were collected from a peripheral vein of neonates under aseptic technique with suspected sepsis for CBC, CRP and blood cultures. Approximately $5 \mathrm{~mL}$ of blood was taken from a peripheral vein and sent for laboratory for biochemical and microbiological examinations and subsequent cultivation.

The collected blood samples cultured aerobically at $37^{\circ} \mathrm{c}$. The cultures were observed daily in the first 3 days to detect any bacterial growth which can be elicited by the presence of any one of the following: Hemolysis, air bubbles and coagulation of broth. Meanwhile, subcultures were made on enriched selective media such as blood, chocolate, MacConkey, and mannitol salt agar plates and examined for growth after 24 to 48 hours of incubation. This protocol was repeated till the $7^{\text {th }}$ day before blood culture was considered to be free of bacteria. The obtained positive cultures were identified by standard techniques including: Gram staining, colony characteristics, and biochemical properties such as catalase, coagulase, DNase production, growth on mannitol salt agar, and hemolytic activity on blood agar plates for Gram positive bacteria while for Gram negative bacteria the triple sugar iron, motility, indole, citrate utilization, urease, oxidase and hydrogen sulphide production, Voges-Proskauer test and growth on cetrimide agar were used [15].

\section{Statistical analysis}

The collected data was analyzed by using Statistical Package for the Social Sciences (SPSS) version 20 software and the variables were expressed as frequencies and percentages. Chi square test was used to study the relationship between variables. A p-value of less than 0.05 was regarded statistically significant.

Ethical Considerations: The research will not expose patients to further risk. Only the main investigator has the right to access the patient's information. The research was conducted after the approval of the research proposal by the ethical committee of AlBatool teaching hospital.

\section{Results}

A sample of 1200 neonates, who were admitted to the neonatal intensive care unit in Al Batool teaching hospital in the period extending from the $1^{\text {st }}$ of Dec. 2018 till the $1^{\text {st }}$ of Oct. 2019, was selected. 
Table (1): The frequencies and percentages of neonatal sepsis and the possible risk factors

\begin{tabular}{|c|c|c|c|}
\hline \multicolumn{2}{|c|}{ Data } & \multirow{2}{*}{$\begin{array}{c}\begin{array}{c}\text { Frequency } n= \\
1200\end{array} \\
106\end{array}$} & \multirow{2}{*}{$\begin{array}{c}\begin{array}{c}\text { Percentage } \\
100.0 \%\end{array} \\
8.8 \%\end{array}$} \\
\hline Cases & Sepsis & & \\
\hline & No sepsis & 1094 & $91.2 \%$ \\
\hline \multirow[t]{2}{*}{ Gestational age } & Preterm & 387 & $32.2 \%$ \\
\hline & Term & 813 & $67.8 \%$ \\
\hline \multirow{2}{*}{$\begin{array}{l}\text { State of } \\
\text { membranes }\end{array}$} & Ruptured & 394 & $32.8 \%$ \\
\hline & Intact & 806 & $67.2 \%$ \\
\hline \multirow{2}{*}{$\begin{array}{l}\text { Mode of } \\
\text { delivery }\end{array}$} & Caesarian & 429 & $35.8 \%$ \\
\hline & Normal & 771 & $64.2 \%$ \\
\hline \multirow[t]{2}{*}{ Maternal fever } & Present & 392 & $32.7 \%$ \\
\hline & Absent & 808 & $67.3 \%$ \\
\hline \multirow[t]{2}{*}{ Sex } & Male & 548 & $54.3 \%$ \\
\hline & Female & 652 & $61.7 \%$ \\
\hline
\end{tabular}

In this table descriptive statistics revealed that: $8.8 \%$ of neonates had neonatal sepsis, $32.2 \%$ were preterm, $32.8 \%$ were reported to have premature rupture of amniotic membrane, $35.8 \%$ were product of caesarian sections and $32.7 \%$ of cases had a history of maternal fever. Among the studied sample there were $54.3 \%$ male neonates.

Table (2): The relationship between neonatal sepsis and the possible risk factors

\begin{tabular}{|c|c|c|c|c|c|c|}
\hline \multicolumn{2}{|l|}{ "Risk factors } & Sepsis & No sepsis & Total & P-values & RR \\
\hline \multirow[t]{3}{*}{ Gestational age } & Preterm & $76(71.7 \%)$ & $311(28.4 \%)$ & $387(32.2 \%)$ & \multirow[t]{3}{*}{0.0001} & \multirow[t]{3}{*}{6.37} \\
\hline & Term & $30(28.4 \%)$ & $783(71.6 \%)$ & $813(67.8 \%)$ & & \\
\hline & Total & $\begin{array}{l}106(100 \%) \\
\end{array}$ & $21094(100 \%)$ & $\frac{1200(100 \%)}{}$ & & \\
\hline \multirow[t]{3}{*}{ State of membranes } & R Ruptured & $70(66 \%)$ & $324(29.6 \%)$ & $394(32.8 \%)$ & \multirow[t]{3}{*}{0.0001} & \multirow[t]{3}{*}{4.62} \\
\hline & Intact & $36(34 \%)$ & $770(70.4 \%)$ & $806(67.2 \%)$ & & \\
\hline & Total & $106(100 \%)$ & $1094(100 \%)$ & $1200(100 \%)$ & & \\
\hline \multirow[t]{3}{*}{ Mode of delivery } & Caesarian & $867(63.2 \%)$ & $362(33.1 \%)$ & $4429(35.8 \%)$ & \multirow[t]{3}{*}{0.0001} & \multirow[t]{3}{*}{3.47} \\
\hline & Normal & $39(36.8 \%)$ & $732(66.9 \%)$ & $7771(64.2 \%)$ & & \\
\hline & Total & $106(100 \%)$ & $1094(100 \%)$ & $1200(100 \%)$ & & \\
\hline \multirow[t]{3}{*}{ Maternal fever } & Present & $69(65.1 \%)$ & $323(29.5 \%)$ & $392(32.7 \%)$ & \multirow[t]{3}{*}{0.0001} & \multirow[t]{3}{*}{4.45} \\
\hline & Absent & $37(34.9 \%)$ & $771(70.5 \%)$ & $808(67.3 \%)$ & & \\
\hline & Total & $8106(100 \%)$ & $1094(100 \%)$ & $1200(100 \%)$ & & \\
\hline \multirow[t]{3}{*}{ Gender } & Male & $52(49.1 \%)$ & $496(45.3 \%)$ & $548(45.7 \%)$ & \multirow[t]{3}{*}{0.463} & \multirow[t]{3}{*}{0.861} \\
\hline & Female & $54(50.9 \%)$ & $598(54.7 \%)$ & $652(54.3 \%)$ & & \\
\hline & Total & $\frac{106(100 \%)}{10 \%}$ & 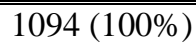 & $1200(100 \%)$ & & \\
\hline
\end{tabular}

Analytic statistics revealed that there was a indicated that the chance of development of highly significant relationship between the occurrence of neonatal sepsis and the gestational age as the p-value was equal to neonatal sepsis in preterm neonates increased 0.0001 . The relative risk was 6.37 which by about six times more than that in term neonates. 
In addition there were highly significant relationships between the developments of neonatal sepsis and each of the state of the amniotic membranes, mode of delivery and the history of maternal fever as the p-values were equal to 0.0001 for each. The relative risks of the occurrence of neonatal sepsis in reference to the previously mentioned risk factors were $4.62,3.47$ and 4.45 respectively. This indicates that the chance of development of neonatal sepsis in neonates with maternal history of ruptured amniotic membranes was about four and a half time greater than those with maternal history of intact amniotic membranes while the chance of those who were products of caesarian sections was about three and a half time greater than those who were products of normal vaginal delivery.

Furthermore the chance of development of neonatal sepsis in neonates with history of maternal fever increased by about four and a half time greater than those with no history of maternal fever. In the other hand there was insignificant relationship between gender of the neonates and the development of neonatal sepsis as the p-value was equal to 0.463 .

\section{Discussion}

Neonatal sepsis is one of the challenging conditions for pediatricians since it is regarded as the most common cause of morbidity and mortality in the neonatal intensive care units. As a wrong diagnosis result in prolonged hospital stay, treatment of non-sepsis neonates, emergence of microorganism resistant to various antibiotics and financial burden especially in poor society sensitive and specific laboratory investigations would be useful to diagnose and to decide when to start antimicrobial agents to avoid these challenges. The incidence of neonatal sepsis is different among different regions in the world [16]. This study showed that the incidence rate of neonatal sepsis in the neonatal intensive care unit in Al-Batool teaching hospital in Diyala governorate in Iraq was $8.8 \%$. In addition our study revealed that there were highly significant relationships between each of gestational age, state of amniotic membranes, mode of delivery and maternal fever with the development of neonatal sepsis.

These results run in parallel with the results mentioned by Medhat et al.(2016) [17] which stated that the prevalence of septicemia in neonatal intensive care units in South Sinai state hospitals was about $8.6 \%$ due to the abundance of risk factors in this area. Similarly Sorsa (2019) [18] stated that the incidence of neonatal sepsis was $9.7 \%$ and it was strongly associated with obstetrical factors especially gestational age and prolonged premature rupture of amniotic membranes. Behmadi et al. (2016) [16] stated that the incidence rate of neonatal sepsis in the neonatal intensive care unit was $11.9 \%$. In the other hand Shehab El-Din et al. (2015) [19] found that the incidence rate of neonatal sepsis was $40.7 \%$ and it was associated with the mode of delivery as neonatal sepsis appeared to be higher in neonates who were product of caesarian section than via normal vaginal delivery but had insignificant relation to the gender of neonates. Getabelew et al. 
(2018) [20] stated that the overall prevalence of neonatal sepsis was $77.9 \%$. G/Eyesus et al. (2017) [21] reported that the incidence rate of neonatal sepsis in the neonatal intensive care unit was $46.6 \%$ and it showed significant relationship with each of gestational age and mode of delivery. Zakariya et al. (2010) [22] found that $41.6 \%$ of the studied sample were culture proven neonatal sepsis.

In developed countries culture proven sepsis was about 2.2 to 8.6 for each 1000 live births [23].

These differences among results might be due to the fact that the rate of occurrence of neonatal sepsis varies greatly in different countries, regions and hospitals as it depends greatly on the quality of life, standard measures of health care and hospital services applied in each country. In addition these can be due to the proper application of the preventive measures that were used in our neonatal intensive care unit and involvement of all paramedical staffs in the infection control programs.

\section{Conclusions}

The occurrence of neonatal sepsis depends on the presence of many factors that could be prenatal, perinatal and postnatal. In addition to that the infection control programs play an important role in controlling neonatal sepsis in the neonatal intensive care units. Therefore the incidence rate of neonatal sepsis reflect the quality of the provided health services in the health institutions and this might explain the relatively accepted rate of sepsis in our institution in relation to other studies as it was $8.8 \%$.

\section{Recommendation}

Engagement of paramedical staffs in regular educational sessions of infection control program and strict application of infection control programs play important role in reduction of the incidence rate of neonatal sepsis. In addition to that the proper use of antimicrobial agents will avoid drug resistance.

\section{References}

[1]Wu, JH, Chen, CY, Tsao, PN, Hsieh, WS, and Chou, HC, Neonatal Sepsis: A 6-Year Analysis in a Neonatal Care Unit in Taiwan. Pediatrics \& Neonatology, (2009); 50(3): 8895.

[2]UNICEF, WHO, The World Bank, and The United Nations, Levels and Trends in Child Mortality, UNICEF, New York, NY, USA, 2011.

[3]Black, RE, Cousens, S, Johnson, HL, Lawn, JE, Rudan, I, Bassani, DG, et al. Global, regional, and national causes of child mortality in 2008: a systematic analysis. The Lancet, (2010); 375(9730): 1969-1987.

[4]Stoll, BJ, Hansen, N, Fanaroff, AA, Wright, LL, Carlo, WA, Ehrenkranz, RA, et al. Changes in Pathogens Causing EarlyOnset Sepsis in Very-Low-Birth-Weight Infants. New England Journal of Medicine, [online] (2002); 347(4): 240-247. Available at:https://www.nejm.org/doi/full/10.1056/NE JMoa012657 [Accessed 26 Nov. 2019]. [5]Ferreira, RC, Mello, RR, and Silva, KS, Neonatal sepsis as a risk factor for neurodevelopmental changes in preterm infants with very low birth weight. Jornal de Pediatria, [online] (2014); 90(3): 293-299. 
Availableat:https://www.sciencedirect.com/sc ience/article/pii/S0021755714000187

[Accessed 26 Nov. 2019].

[6]Dammann, O, Kuban, KCK, and Leviton, A, Perinatal infection, fetal inflammatory response, white matter damage, and cognitive limitations in children born preterm. Mental Retardation and Developmental Disabilities Research Reviews, [online] (2002); 8(1): 4650. Available

at: https://onlinelibrary.wiley.com/doi/abs/10.10 02/mrdd.10005 [Accessed 26 Nov. 2019].

[7]Edwards MS, and Baker CJ, Sepsis in the newborn. In: Krugman, S, Gershon, AA, Hotez, PJ, and Katz, SL, Krugman's infectious diseases of children. Philadelphia: Mosby, (2004).

[8]Patel, SJ, and Saiman, L, Antibiotic Resistance in Neonatal Intensive Care Unit Pathogens: Mechanisms, Clinical Impact, and Prevention Including Antibiotic Stewardship. Clinics in Perinatology, (2010); 37(3): 547563.

[9]Meshram, RM， Gajimwar, VS, and Bhongade, SD, Predictors of mortality in outborns with neonatal sepsis: A prospective observational study. The Nigerian postgraduate medical journal, [online] (2019); 26(4): 216-222. Available at: https://www.ncbi.nlm.nih.gov/pubmed/31621 661 [Accessed 26 Nov. 2019].

[10]Shrestha, S, Adhikari, N, Rai, B, and Shreepaili, A, Antibiotic resistance pattern of bacterial isolates in neonatal care unit. Journal of Nepal Medical Association, (2010); 50(180).
[11]Ghotaslou, R, Ghorashi, Z, and Nahaei, MR, Klebsiella pneumoniae in Neonatal Sepsis: A 3-Year-Study in the Pediatric Hospital of Tabriz, Iran. Jpn. J. Infect. Dis, [online] (2007); 60: 126-128. Available at: http://www0.nih.go.jp/JJID/60/126.pdf

[Accessed 26 Nov. 2019].

[12]Saiman, L, Infectious Diseases of the Fetus and Newborn Infant. JAMA, (2012); 307(17): 1865.

[13]Egynewborn.org. About EGNN. [online] (2010), Available at: http://www.egynewborn.org/ [Accessed 26 Nov. 2019].

[14]Bizzarro, M, Dembry, L, Baltimore, R, and Gallagher, P, Changing Patterns in Neonatal Escherichia coli Sepsis and Ampicillin Resistance in the Era of Intrapartum Antibiotic Prophylaxis. PEDIATRICS, (2008); 121(4): 689-696.

[15]Jorgensen, JH, Pfaller, MA, Carroll, KC, and American Society For Microbiology Manual of clinical microbiology. Washington, Dc: Asm Press (2015).

[16]Behmadi, Homayoon, et al. "Prevalence and Antibiotic Resistance of Neonatal Sepsis Pathogens in Neyshabour, Iran." Archives of Pediatric Infectious Diseases, 1 Apr. 2016; vol. 4, no. 2, pedinfect.com/en/articles/20291.html, 10.5812/pedinfect.33818. Accessed 22 Nov. 2019.

[17]Medhat, Hisham, et al. "Incidence of Neonatal Infection in South Sinai, Egypt." International Journal of Infection, vol. 4, no.

1, 24 Aug. 2016, 10.17795/iji-36615. Accessed 22 Nov. 2019. 
[18]Sorsa, A, Epidemiology of Neonatal Sepsis and Associated Factors Implicated: Observational Study at Neonatal Intensive Care Unit of Arsi University Teaching and Referral Hospital, South East Ethiopia. Ethiopian journal of health sciences, 2019; 29(3).

[19]Shehab El-Din, Eman M Rabie, et al. "Epidemiology of Neonatal Sepsis and Implicated Pathogens: A Study from Egypt." BioMed Research International, 2015; vol. 2015: 1-11, 10.1155/2015/509484. Accessed 22 Nov. 2019.

[20]Getabelew, Aytenew, et al. "Prevalence of Neonatal Sepsis and Associated Factors among Neonates in Neonatal Intensive Care Unit at Selected Governmental Hospitals in Shashemene Town, Oromia Regional State, Ethiopia, 2017." International Journal of Pediatrics, 2 Aug. 2018; vol. 2018: 1-7, 10.1155/2018/7801272. Accessed 22 Nov. 2019.

[21]G/Eyesus, T, Moges, F, Eshetie, S, Yeshitela, B, and Abate, E, Bacterial etiologic agents causing neonatal sepsis and associated risk factors in Gondar, Northwest Ethiopia. BMC Pediatrics, (2017); 17(1). [22]Zakariya, BP, Bhat, V, Harish, BN, Arun Babu, T, and Joseph, NM, Neonatal Sepsis in a Tertiary Care Hospital in South India: Bacteriological Profile and Antibiotic Sensitivity Pattern. The Indian Journal of Pediatrics, [online] (2010); 78(4): 413-417. Available at:https://link.springer.com/article/10.1007/s1 2098-010-0314-8 [Accessed 8 Jun. 2019].
[23]Mihatov Stefanovic, I, Neonatal sepsis. Biochemia Medica, (2011): pp.276-281. 